Original

\title{
Renal Tubular Cyst Formation in Newborn Rats Treated with p-Cumylphenol
}

\author{
Tomomi Nakazawa ${ }^{1}$, Kenichiro Kasahara ${ }^{1}$, Shinichiro Ikezaki ${ }^{1}$, Yuko Yamaguchi ${ }^{1}$, \\ Hiroshi Edamoto ${ }^{1}$, Nobuo Nishimura ${ }^{1}$, Megumi Yahata ${ }^{1}$, Kazutoshi Tamura ${ }^{1}$, \\ Eiichi Kamata², Makoto Ema² and Ryuichi Hasegawa² \\ ${ }^{1}$ Bozo Research Center Inc., 1284 Kamado, Gotemba, Shizuoka 412-0039, Japan \\ ${ }^{2}$ National Institute of Health Sciences, 1-18-1 Kamiyoga, Setagaya-ku, Tokyo 158-8501, Japan
}

\begin{abstract}
In this study, we investigated the sequential changes in the development of renal tubular cysts in newborn rats treated with p-cumylphenol (PCP). Fifteen animals per sex were treated orally with $300 \mathrm{mg} / \mathrm{kg} / \mathrm{day}$ of PCP for up to 18 days from postnatal day (PND) 4 and were sacrificed on PNDs 8, 12, 19 and 22 and after a 7 day recovery period. On PNDs 8 and 12, slight dilatation of the collecting ducts was frequently observed in the medulla and slight papillary necrosis was also noted in some cases. These dilated collecting ducts were lined with slightly hyperplastic epithelial cells. On PNDs 19 and 22, multiple large cystic changes arising from the collecting ducts in the outer medulla were seen. These cystically dilated ducts were also lined with hyperplastic epithelial cells. During the dosing period, the labeling index of proliferating cell nuclear antigen in the collecting duct epithelium was higher in the PCP-treated group than in the control group at all time points. After a 7 day recovery period, the cystic change still remained, although the cell density was decreased and the epithelial cells became flattened. On the other hand, basophilic tubules with peritubular lymphoid cell infiltration were multifocally observed in the cortex. In conclusion, PCP induced multiple renal cysts that developed in the collecting ducts of the outer medulla in neonatal rats, and it is suggested that epithelial cell proliferation may play some roles in the induction of cystic lesions. (J Toxicol Pathol 2009; 22: 125-131)
\end{abstract}

Key words: p-cumylphenol, newborn rats, polycystic kidney

\section{Introduction}

Polycystic kidney is a disease characterized by the formation of multiple cysts or cystic changes of the renal uriniferous tubules that has been noted in various animal species. Common types of renal polycystic kidney disease (PKD) in humans include autosomal recessive polycystic kidney disease (ARPKD), autosomal dominant polycystic kidney disease (ADPKD $)^{1,2}$ and medullary cystic disease complex $^{3}$. Similar counterparts are known in other animal species, such as mice, rats, rabbits, springboks, dogs and swine $^{4,5}$. Many investigators have reported that PKDs can be induced by various chemicals, including diphenylamine ${ }^{6}$, nordihydroguaiaretic acid ${ }^{7}$, diphenylthiazole ${ }^{8}$, alloxan ${ }^{9}$, streptozotocin $^{9}$, ferric-nitrilotriacetate ${ }^{9}$ and 2-amino-4, 5diphenylthiazole ${ }^{10}$ in young and adult animals and paranonylphenol ${ }^{11}$ and tetrabromobisphenol $\mathrm{A}^{12}$ in newborn animals. However, the mechanisms responsible for the

Received: 8 January 2009, Accepted: 19 February 2009

Mailing address: Tomomi Nakazawa, Bozo Research Center Inc., 1284

Kamado, Gotemba, Shizuoka 412-0039, Japan

TEL: 81-550-82-9914 FAX: 81-550-82-9915

E-mail: path@bozo.co.jp formation of renal cysts by these compounds are not yet clearly understood, although it has been said that formation of renal cysts may be associated with cell proliferation, alteration of tubular basement membrane and $\mathrm{Na} / \mathrm{K}$ ATPase localization and/or activity in the target site of the tubules. On the other hand, it has been suggested that the estrogen receptors located in the kidneys mediate the cell proliferation, and Concolino et al. reported that the cell proliferation may be a potential cause of acquired cystic kidney disease ${ }^{13}$. In addition, ciliary dysfunction may also play a key role in cyst development, since the cilia contribute to regulation of intratubular fluid flow ${ }^{14-18}$.

The chemical p-cumylphenol (PCP), also known as p( $\alpha, \alpha$-dimethylbenzyl) phenol, is widely used as a material for polycarbonate plastics, surfactants, fungicides and preservatives. Hasegawa et al. ${ }^{19}$ investigated the susceptibility of newborn rats to 6 industrial chemicals including PCP by comparing the toxicity in newborns with that in young animals. They reported that newborn rats treated with 100 or $300 \mathrm{mg} / \mathrm{kg}$ of PCP by gavage for 18 days from postnatal day (PND) 4 developed cystic tubular dilatation in the kidney at the end of the dosing period and were not completely recovered from the lesion at 9 weeks after withdrawal of PCP. They also reported that PCP 


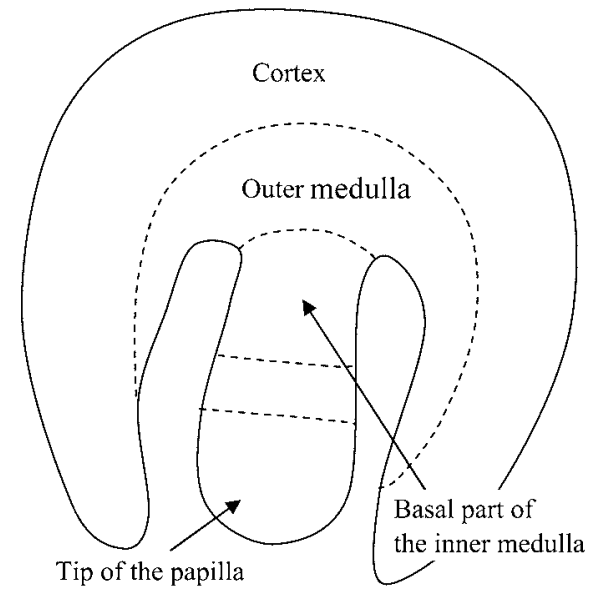

Fig. 1. Areas that were observed histologically and immunohistochemically: cortex, the outer medulla, basal part of the inner medulla and tip of the papilla.

affected the histology of the ovary and uterus, probably due to its estrogenic activity.

In the present study, we investigated the effects of timecourse histological changes and cell proliferative activity on the development of renal tubular cyst formation in newborn rats treated with PCP for up to 18 days from PND 4.

\section{Materials and Methods}

\section{Animals and housing conditions}

Six pregnant rats of the Sprague-Dawley (Crl:CD) strain were purchased from Charles River Japan Inc. (Kanagawa, Japan) on day 18 of gestation and allowed to deliver spontaneously. The date of birth was defined as PND 0 . All newborn rats were separated from their dams on PND 3 , and those in good health were pooled according to sex and assigned to the following study. Five foster mothers were selected based on health and nursing conditions, and each mother was allowed to suckle 5 males and 5 females.

All animals were housed in an environmentally controlled room $\left(23 \pm 3^{\circ} \mathrm{C}\right.$ with a relative humidity of $50 \pm$ $20 \%$, a ventilation rate of 10-15 times per hour and a 12:12 hr light/dark cycle). All dams and pups of the recovery group were allowed free access to sterilized basal diet (CRF1, Oriental Yeast Co., Ltd., Tokyo, Japan) and tap water. The experiment was carried out in accordance with the Guide for Animal Experimentation of Bozo Research Center Inc.

\section{Chemicals}

PCP (CAS no. 599-64-4, Lot no. 101002, purity: 99.88\%) was obtained from Sun Techno Chemical Inc. (Tokyo, Japan). The test article was dissolved in olive oil. The solutions were prepared at least once a week and kept cool and dark until use.

\section{Experimental design}

A total of 50 animals consisting 25 male and 25 female newborn rats were selected on PND 3 and assigned to each group of the following study by stratified random sampling based on body weight. Two animals per sex for each dosing period group were treated with olive oil and served as the vehicle control group, and 3 animals per sex for each dosing period group were treated with $300 \mathrm{mg} / \mathrm{kg} /$ day of PCP by gavage. The dose level of PCP was selected based on the results previously reported by Hasegawa et al. ${ }^{19}$.

Clinical signs and body weights were examined periodically throughout the experimental period. Animals were euthanized by exsanguination under deep ether anesthesia and sacrificed on PNDs 8, 12, 19 and 22 and after a 7 day recovery period. Immediately after macroscopic observation, the kidneys were weighed, fixed in $10 \%$ buffered formalin, embedded in paraffin wax and sectioned. Paraffin sections were stained with hematoxylin and eosin for microscopic examination. The results of histological examinations were divided into areas of the cortex, outer medulla, basal part of the inner medulla and tip of the papilla (Fig. 1). Moreover, the sections were also subjected to immunohistochemistry for proliferating cell nuclear antigen (PCNA) by the LSAB method (Dako LSAB2 kit; Dako, Japan) using monoclonal mouse antibody against PCNA diluted 1:200 (Dako, Japan). The number of PCNA-positive nuclei was counted in the same areas as used for histological examination and expressed as a PCNA-labeling index (\%) without statistical analysis.

\section{Results}

\section{Clinical observations and body weights}

No deaths or abnormal signs were observed in animals from both of the control and PCP-treated groups throughout the experimental period. In the PCP-treated group, body weight gain was slightly suppressed during the dosing period, but it recovered to the control level after the withdrawal of PCP.

\section{Kidneys weights}

In the PCP-treated group, the absolute weight of the kidneys markedly increased in comparison with that in the control group on PNDs 19 and 22 and after a 7 day recovery period (Fig. 2). The weight was 1.6/1.8 (male/female), 2.0/ 1.7 and 1.9/1.4 times heavier on PNDs 19 and 22 and after a 7 day recovery period, respectively. Similar changes were detected in the relative weight of the kidneys (kidney weight/ body weight).

\section{Gross findings}

Corresponding to the changes in the weight of the kidneys, enlargement of the kidneys was observed on PNDs 19 and 22 and after a 7 day recovery period. There were no abnormal findings in the PCP-treated group examined on PNDs 8 and 12 as well as in the control group. 

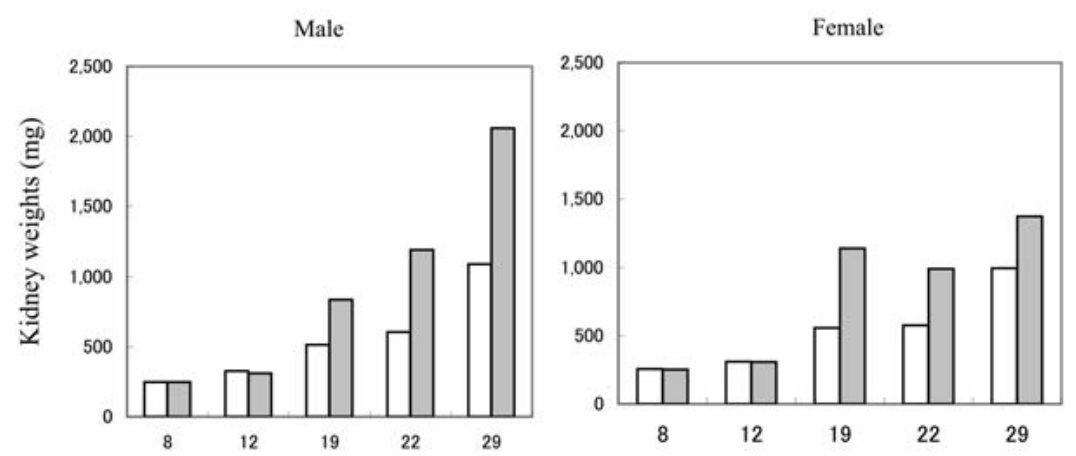

Fig. 2. Effects of neonatal exposure to PCP on kidney weights. Each column represents a mean value from 2 and 3 rats in the control and PCPtreated groups, respectively. $\square: 0 \mathrm{mg} / \mathrm{kg}$ PCP, $\square: 300 \mathrm{mg} / \mathrm{kg}$ PCP, PND: Postnatal day (PND 29 is a recovery Day 7).

Table 1. Effect of Neonatal Exposure to PCP on Histopathological Findings

\begin{tabular}{|c|c|c|c|c|c|c|c|c|c|c|c|}
\hline & \multirow[b]{3}{*}{ No.of rats } & \multicolumn{5}{|c|}{ Male } & \multicolumn{5}{|c|}{ Female } \\
\hline & & \multicolumn{4}{|c|}{ Administration period } & \multirow{2}{*}{$\frac{\text { Recovery }^{\text {a) }}}{3}$} & \multicolumn{4}{|c|}{ Administration period } & \multirow{2}{*}{$\frac{\text { Recovery }}{3}$} \\
\hline & & 3 & 3 & 3 & 3 & & 3 & 3 & 3 & 3 & \\
\hline & Findings & 8 & 12 & 19 & 22 & 29 & 8 & 12 & 19 & 22 & 29 \\
\hline \multirow[b]{2}{*}{ Tip of papilla } & \multirow{2}{*}{$\begin{array}{l}\text { Dilatation, papillary duct } \\
\text { Necrosis / neutrophil infiltration } \\
\text { (with / without reactive hyperplasia) }\end{array}$} & - & - & $\pm \sim+$ & $\pm \sim+$ & $\pm \sim+$ & - & - & $\pm \sim+$ & + & $\pm \sim+$ \\
\hline & & $-\sim \pm$ & - & - & - & - & $-\sim \pm$ & $-\sim \pm$ & - & - & - \\
\hline $\begin{array}{l}\text { Basal part of } \\
\text { inner medulla }\end{array}$ & Dilatation, collecting duct & $-\sim \pm$ & $-\sim \pm$ & $\pm^{\dagger}$ & $\pm^{\dagger}$ & $-\sim \pm$ & $\pm^{\dagger}$ & $-\sim \pm^{\dagger}$ & $\pm \sim+^{\dagger}$ & $\pm \sim+^{\dagger}$ & $-\sim \pm$ \\
\hline \multirow{4}{*}{ Outer meulla } & \multirow{4}{*}{$\begin{array}{l}\text { Dilatation, cystic, collecting duct } \\
\text { Dilatation, collecting duct } \\
\text { Cell debris, luminal } \\
\text { (cystic dilated collecting ducts) } \\
\text { Neutrophil infiltration } \\
\text { (surrounding cystic dilated collecting duct) }\end{array}$} & - & - & $++^{\ddagger}$ & $++^{\ddagger}$ & ++ & - & - & $++^{\ddagger}$ & $++^{\ddagger}$ & $+\sim++$ \\
\hline & & - & - & $\pm \sim+^{\dagger}$ & $\pm \sim+^{+}$ & $-\sim \pm$ & $-\sim \pm$ & - & $\pm \sim+^{\dagger}$ & $\pm \sim+^{\dagger}$ & $-\sim \pm$ \\
\hline & & - & - & \pm & $-\sim \pm$ & \pm & - & - & $-\sim \pm$ & $-\sim \pm$ & $-\sim \pm$ \\
\hline & & - & - & \pm & $-\sim \pm$ & \pm & - & - & $-\sim \pm$ & $-\sim \pm$ & $-\sim \pm$ \\
\hline \multirow{2}{*}{ Cortex } & \multirow{2}{*}{$\begin{array}{l}\text { Basophilia, tubular, multifocal } \\
\text { Cell infiltration, lymphocytic }\end{array}$} & - & - & - & - & + & - & - & - & - & $-\sim \pm$ \\
\hline & & - & - & - & - & $\pm \sim+$ & - & - & - & - & \pm \\
\hline
\end{tabular}

a) After a 7 day recovery period. ${ }^{\text {b) }}$ Postnatal day. ${ }^{\dagger}$ Lined with slightly hyperplastic epithelial cells. ${ }^{\ddagger}$ Lined with mild (or moderately) hyperplastic epithelial cells. Severity grade, -: no remarkable changes, \pm : slight, +: mild, ++: moderate.

\section{Histopathological findings}

The histological findings observed in the PCP-treated group are shown in Table 1 and Figs. 3 and 4.

On PNDs 8 and 12, slightly dilated collecting ducts lined with slightly hyperplastic epithelium were frequently observed in the basal part of the inner medulla (Fig. 3a, b, c). In the tip of the papilla, necrosis and neutrophil infiltration and reactive hyperplasia of the tubular epithelial cells were observed in a few animals (Fig. 3d).

On PNDs 19 and 22, dilatation of the collecting ducts in the basal part of the medulla slightly progressed, and markedly dilated cystic lesions were produced mainly in the outer medulla (Fig.3e). These ducts were lined with hyperplastic epithelial cells and occasionally contained desquamated epithelial cells (Fig. 3f). Such a hyperplastic change was most prominent in the outer medulla. In addition, focal neutrophil infiltration was observed around the cystically dilated ducts in some animals. In the tip of the papilla, slightly dilated papillary ducts were also observed.

After a 7 day recovery period, the cystically dilated collecting ducts still remained in the outer medulla, although the cell density was reduced and the epithelial cells became flattened (Fig. 3g, h). On the other hand, in the cortex, multifocal basophilic tubules appeared with peritubular lymphoid cell infiltration.

In the control group, there were no histopathological changes throughout the experimental period.

\section{PCNA-labeling index}

In the PCP-treated group, at all time points from PNDs 8 to 22 (except for the basal part of the inner medulla of females on PND 8) the PCNA-labeling index in the epithelia 

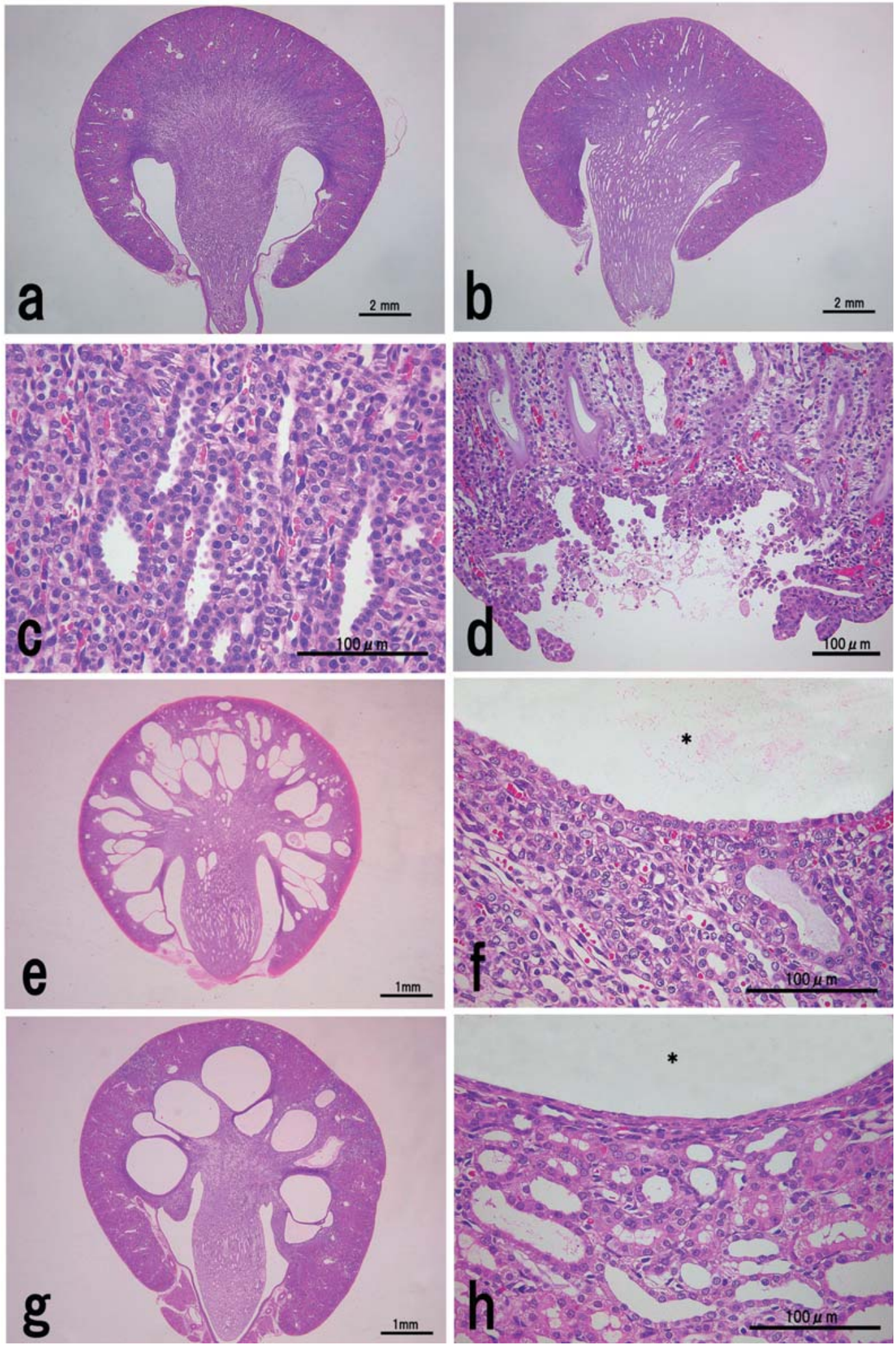

Fig. 3. Photomicrographs of kidneys with H.E.staining. (a) Control and (b) PCP-treated neonates on PND 12. Slightly dilated collecting ducts are seen in the basal part of the medulla in b. (c, d) Higher magnification images of b. Slightly dilated collecting ducts in the basal part of the medulla, and necrosis in the tip of the papilla. (e) PCP-treated neonates on PND 19. Cystic dilatation of the collecting ducts in the outer medulla. (f) Higher magnification image of e. Cyst lined with a hyperplastic epithelium. (g) PCP-treated neonates after a 7 day recovery period. Cystic dilatation of the collecting ducts in the medulla. (h) Higher magnification image of g. Cyst lined with a flattened epithelium. *: cyst lumen. 

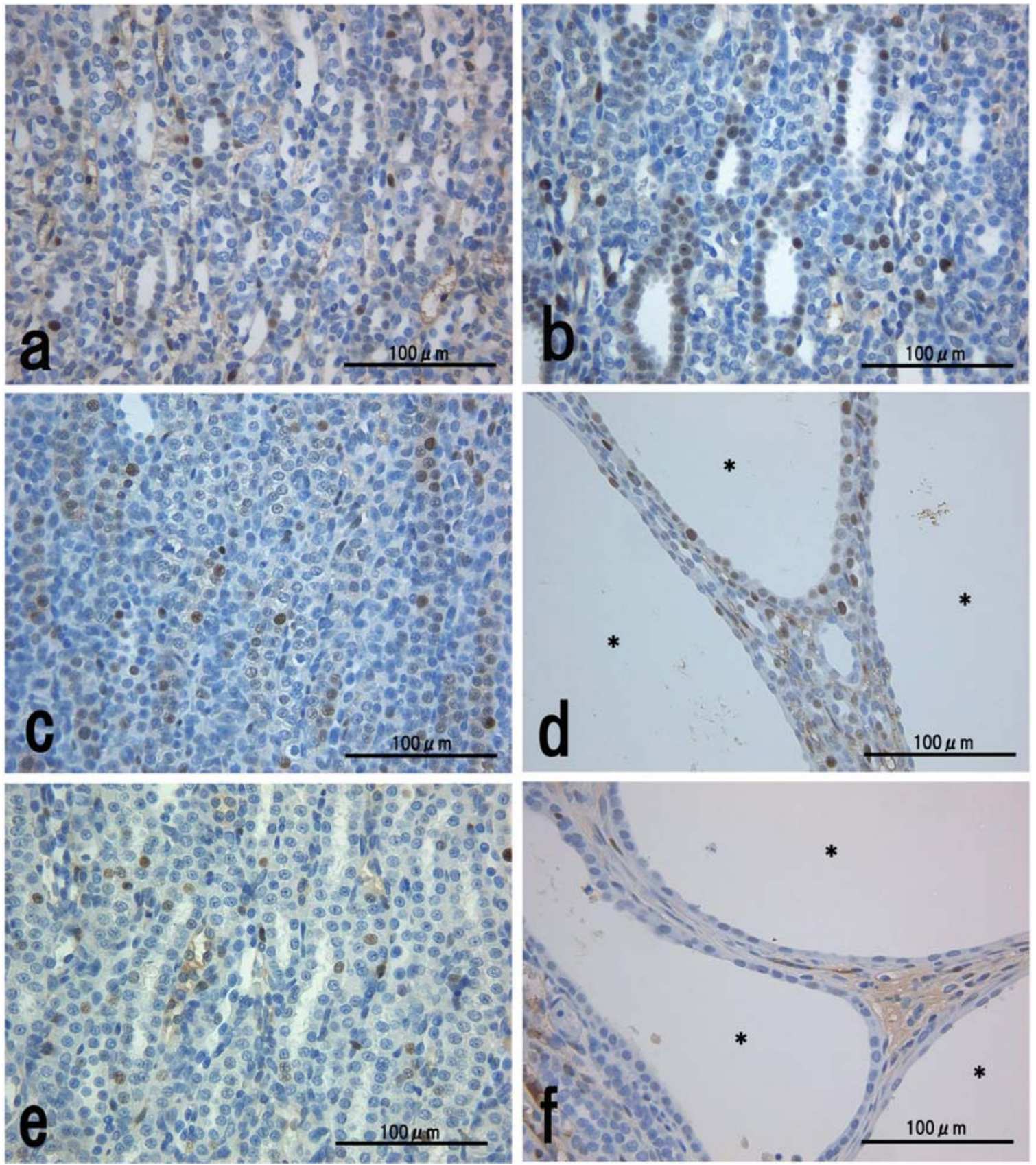

Fig. 4. Immunohistochemistry for PCNA in the kidneys. The basal part of the inner medulla of (a) Control and (b) PCP-treated neonates on PND 12. An increase of PCNA positive cells is seen in b. The outer medulla of (c) Control and (d) PCP-treated neonates on PND 19. An increase of PCNA positive cells is seen in d. (e) Control and (f) PCP-treated neonates after a 7 day recovery period. The number of PCNA positive cells is reduced in (f). *: cyst lumen.

of the collecting ducts, including the cystically dilated ones, significantly increased, especially in the outer medulla (Fig. 4a, b, c, d and Fig. 5). After a 7 day recovery period, the labeling index was comparable to that in the control group (Fig. 4e, $\mathrm{f}$ and Fig. 5).

\section{Discussion}

In the present study, the development of PCP-induced renal tubular cyst formation was examined in newborn rats treated with $300 \mathrm{mg} / \mathrm{kg} / \mathrm{day}$ of PCP from PND 4 up to PND 22.

In the PCP-treated group, body weight gain was slightly suppressed during the dosing period, however, it recovered to the normal level following the withdrawal of PCP. On the other hand, the kidney weight in the PCP-treated group was heavier than that in the control group, not only on PNDs 18 and 22, but also after a 7 day recovery period, and these 

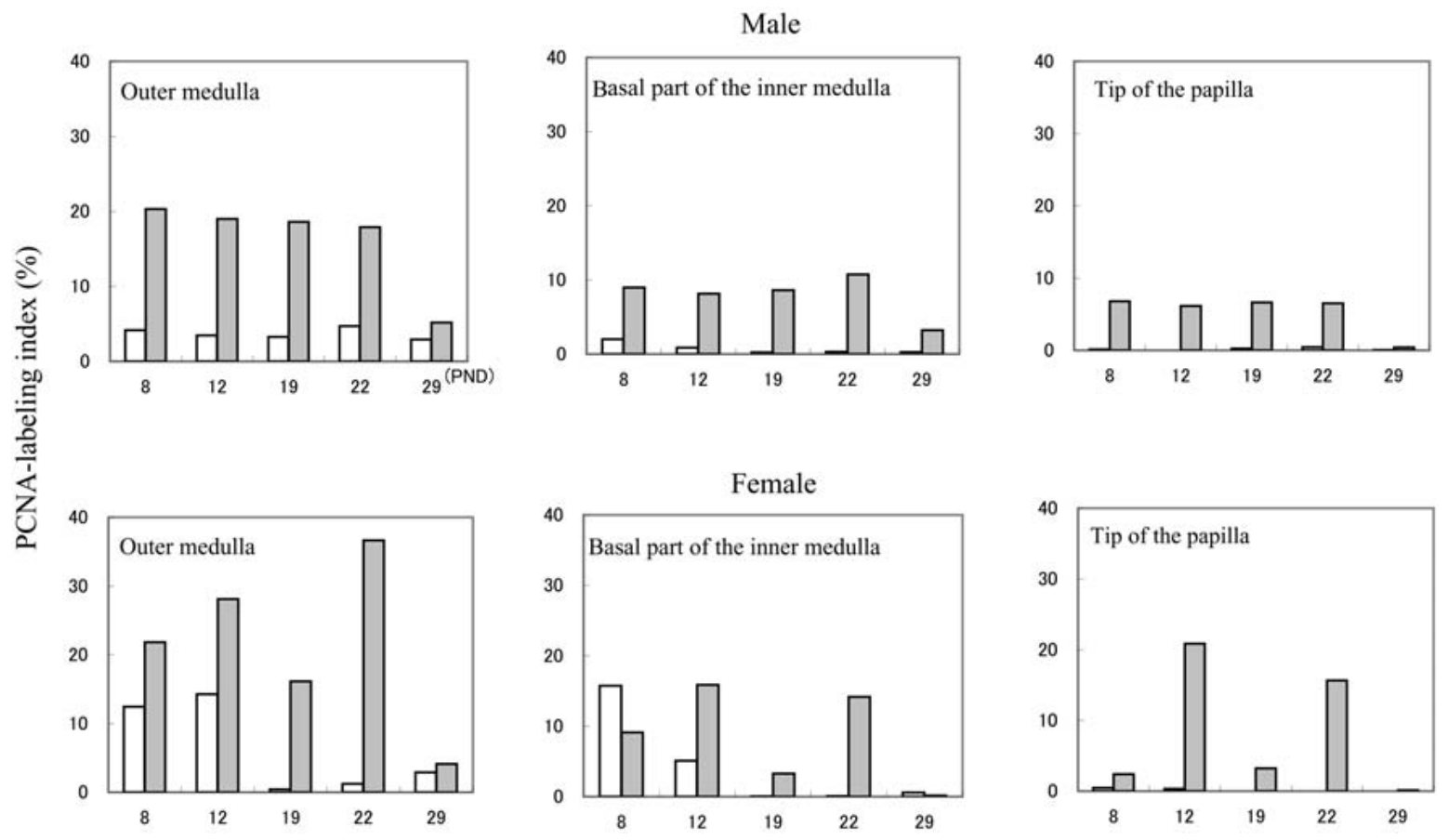

Fig. 5. Effects of neonatal exposure to PCP on the PCNA-labeling indices in the kidneys. $\sqsubset: 0 \mathrm{mg} / \mathrm{kg}$ PCP, $\square: 300 \mathrm{mg} / \mathrm{kg}$ PCP, PND: Postnatal day (PND 29 is recovery Day 7).

changes in kidney weight were considered to be related to the histological changes in the kidney noted below.

Slight dilatation of the collecting ducts in the medulla was observed on PND 8, although no distinct cystic lesions were present. After that, some dilated lesions located mainly in the outer medulla progressed to form multiple large cystic lesions. After a 7 day recovery period, the cystic change was still observed, indicating that PCP-induced cystic lesions are slow to recover. On the other hand, multifocal basophilic tubules appeared in the cortex after PCP withdrawal, although the basophilic tubules did not appear to be related to the cystic lesions, since no predictive changes of this lesion were observed on PNDs 19 and 22. Papillary damage, such as neutrophil infiltration and necrosis, was observed on PNDs 8 and 12, but not after PND 19. This change may be related to cyst formation, but the exact relationship between them is still obscure.

Dilated collecting ducts were generally lined with hyperplastic epithelial cells until the end of the dosing period and occasionally accompanied by slight peritubular inflammatory cell infiltration. Such hyperplastic change in the collecting duct epithelia was most prominent in the outer medulla, and it became more prominent on PNDs 19 and 22 compared with PNDs 8 and 12. This corresponded well with the results of the PCNA-labeling index in the collecting duct epithelia. Therefore, it is reasonable to consider that there may be a correlation between proliferation of collecting duct epithelial cells and dilatation of the collecting ducts.

As mentioned before, PKD has been induced by diphenylamine ${ }^{6}$, nordihydroguaiaretic acid ${ }^{7}$, diphenylthiazole ${ }^{8}$, alloxan ${ }^{9}$, streptozocin ${ }^{9}$, ferricnitrilotriacetate ${ }^{9}$ and 2-amino-4,5-diphenylthiazole ${ }^{10}$ in young and adult animals and para-nonylphenol ${ }^{11}$ and tetrabromobisphenol $\mathrm{A}^{12}$ in newborn animals. The histological changes induced in newborn rats by paranonylphenol are characterized by numerous large cystic tubules, which develop mainly in the outer medulla and occasionally contain necrotic epithelial cells and neutrophils, and by patchy areas of chronic interstitial nephritis. Similarly, tetrabromobisphenol A induces polycystic lesions with tubular epithelial cell hyperplasia in the cortico-medullary junction. These findings are roughly consistent with those of the present study. Although the pathogenesis of chemically-induced PKD has not yet been fully clarified, possible roles of changes of metabolism in tubular epithelia and/or basement membranes in induction of PKD have been proposed ${ }^{20}$. In addition, renal development together with immature metabolism is responsible for high susceptibility to renal injury by extrinsic toxicants in newborn animals ${ }^{21-24}$. Although these factors should be taken into consideration, the present results suggest that cell proliferation may play some role in cyst formation, since the PCNA-labeling indices of the PCP-treated group were higher than those of the control group even before cyst formation developed. However, the PCNA-labeling indices were increased not only in the outer medulla but also in the inner medulla, which is not a target area for cyst formation. A previous study demonstrated that PCP affects the ovaries and uterus, in which the histological changes include increased number of atretic follicles and decreased number 
of corpus luteum in the ovaries and hypertrophy of the endometrial epithelium in the uterus ${ }^{19}$. These histological findings indicate that PCP may have an estrogenic potential. In connection with this, Latendresse et al. reported that the para-nonylphenol-induced polycystic kidney is influenced by phytoestrogens in the diet ${ }^{11}$. Therefore, the potential estrogenic activity of PCP may also affect renal cyst formation.

In conclusion, neonatal exposure to PCP induced multiple cystic lesions arising mainly in the collecting ducts in the outer medulla. Although it is suggested that epithelial cell proliferation may play some role in the formation of cystic lesions, further studies are needed to clarify the exact mechanisms of PCP-induced renal cyst formation in neonatal rats.

Acknowledgement: The authors thank Dr. Kunio Doi, Emeritus Professor of the University of Tokyo, for critical review of this manuscript.

\section{References}

1. Sweeney WE and Avner ED. Molecular and cellular pathophysiology of autosomal recessive polycystic kidney disease (ARPKD). Cell Tissue Res. 326: 671-685. 2006.

2. Torres VE, Harris PC, and Pirson Y. Autosomal dominant polycystic kidney disease. Lancet 14: 1287-1301. 2007.

3. Hildebrandt $F$ and Omram H. New insights: nephronophthisis-medullary cystic disease. Pediatr Nephrol. 16: 168-176. 2001.

4. Guay-Woodford LM. Murine models of polycystic kidney disease: molecular and therapeutic insights. Am J Physiol Renal Physiol. 285: 1034-1049. 2003.

5. Jones TC, Hunt R, and King NW. Congenital and hereditary anomalies. In: The Urinary System, Veterinary Pathology 6th ed., Cann C (ed), USA: Williams and Wilkins. 11131115, 1997.

6. Gardner Jr KD, Solomon S, Fitzgerrel WW, and Evan AP. Function and structure in the diphenylamine-exposed kidney. J Clin Invest. 57: 796-806. 1976.

7. Evan AP and Gardner Jr KD. Nephron obstruction in nordihydroguaiaretic acid-induced renal cystic disease. Kidney Int 1979; 15: 7-19.

8. Gardner Jr KD and Evan AP. Renal cystic disease induced by diphenylthiazole. Kidney Int. 24: 43-52. 1983.

9. Kovacs J, Zilahy M, Banyasz T, and Comba S. Evaluation of apoptosis and cell proliferation in experimentally induced renal cysts. Urol Res. 26: 411-416. 1998.

10. Tsumatani K, Nakagawa Y, Kitahori Y, Konishi N, Uemura H, Ozono S, Hirao Y, Okajima E, Hirao K, and Hiasa Y. Experimental model of renal tumors in polycystic kidneys: effects of long-term 2-amino-4,5-diphenylthiazole administration in rats treated with $N$-ethyl- $N$-hydroxyethyl nitrosamine. Toxicol Pathol. 25: 363-371. 1997.

11. Latendresse JR, Newbold RR, Weis CC, and Delclos KB.
Polycystic kidney disease induced in F (1) Sprague-Dawley rats fed para-nonylphenol in a soy-free casein-containing diet. Toxicol Sci. 62: 140-147. 2001.

12. Fukuda N, Ito Y, Yamaguchi M, Mitsumori K, Koizumi M, Hasegawa R, Kamata E, and Ema M. Unexpected nephrotoxicity induced by tetrabromobisphenol A in newborn rats. Toxicol Lett. 21: 145-155. 2004.

13. Concolino G, Lubrano C, Ombres M, Santonati A, Flammia GP, and Di Silverio F. Acquired cystic kidney disease: The hormonal hypothesis. Urology. 41: 170-175. 1993.

14. Nauli SM, Alenghat FJ, Luo Y, Williams E, Vassilev P, Li $\mathrm{X}$, Elia $\mathrm{AE}, \mathrm{Lu} \mathrm{W}$, Brown EM, Quinn SJ, Ingber DE, and Zhou J. Polycystins 1 and 2 mediate mechanosensation in the primary cilium of kidney cells. Nat Genet. 33: 129-137. 2003.

15. Yamaguchi T, Pelling JC, Ramaswamy NT, Eppler JW, Wallace DP, Nagao S, Rome LA, Sullivan LP, and Grantham JJ. cAMP stimulates the in vitro proliferation of renal cyst epithelial cells by activating the extracellular signal-regulated kinase pathway. Kidney Int. 57: 14601471. 2000.

16. Nagao S, Yamaguchi T, Kusaka M, Maser RL, Takahashi H, Cowley BD, and Grantham JJ. Renal activation of extracellular signal-regulated kinase in rats with autosomaldominant polycystic kidney disease. Kidney Int. 63: 427437. 2003.

17. Yamaguchi T, Nagao S, Wallace DP, Belibi FA, Cowley BD, Pelling JC, and Grantham JJ. Cyclic AMP activates BRaf and ERK in cyst epithelial cells from autosomaldominant polycystic kidneys. Kidney Int. 63: 1983-1994. 2003.

18. Yamaguchi T, Wallace DP, Magenheimer BS, Hempson SJ, Grantham JJ, and Calvet JP. Calcium restriction allows cAMP activation of the B-Raf/ERK pathway, switching cells to a cAMP-dependent growth-stimulated phenotype. J Biol Chem. 279: 40419-40430. 2004.

19. Hasegawa R, Hirata-Koizumi M, Takahashi M, Kamata E, and Ema M. Comparative susceptibility of newborn and young rats to six industrial chemicals. Congenit Anom. 45: 137-145. 2005.

20. Carone FA, Nakamura S, Punyarit P, Kanwar YS, and Nelson WJ. Sequential tubular cell and basement membrane changes in polycystic kidney disease. J Am Soc Nephrol. 3: 244-253. 1992.

21. Chevalier RL. Pathophysiology of obstructive nephropathy in the newborn. Semin Nephrol. 18: 585-593. 1998.

22. Chevalier RL, Goyal S, and Wolstenholme JT. Obstructive nephropathy in the neonate is attenuated by epidermal growth factor. Kidney Int. 54: 38-47. 1998.

23. Merlet-Benichou C, Gilbert T, Muffat-Joly M, LelieverPegorier M, and Leroy B. Intrauterine growth retardation leads to a permanent nephron deficit in the rat. Pediatr Nephrol. 8: 175-180. 1994.

24. Chevalier RL. Growth factors and apoptosis in neonatal ureteral obstruction. J Am Soc Nephrol. 7: 1098-1105. 1996. 